08

\title{
Структурные и магнитные свойства систем $\mathrm{Al}_{2} \mathrm{O}_{3} / \mathrm{Ge}-p / \mathrm{Al}_{2} \mathrm{O}_{3} / \mathrm{Co}$
}

\author{
(C) А.В. Кобяков, ${ }^{1,2}$ И.А. Турпанов, ${ }^{2}$ Г.С. Патрин, ${ }^{1,2}$ Р.Ю. Руденко, ${ }^{1,2}$ В.И. Юшков, ${ }^{1,2}$ Н.Н. Косырев ${ }^{2,3}$ \\ ${ }^{1}$ Сибирский фредеральный университет, \\ 660041 Красноярск, Россия \\ ${ }^{2}$ Институт фризики им. Л.В. Киренского СО РАН, \\ 660036 Красноярск, Россия \\ ${ }^{3}$ Ачинский фрилиал Красноярского государственного аграрного университета, \\ 662150 Ачинск, Красноярский край, Россия \\ e-mail: nanonauka@mail.ru
}

(Поступило в Редакцию 15 мая 2018 г.)

Представлены экспериментальные результаты для системы $\mathrm{Al}_{2} \mathrm{O}_{3} / \mathrm{Ge}-p / \mathrm{Al}_{2} \mathrm{O}_{3} / \mathrm{Co}$ с буферным слоем из $\mathrm{Al}_{2} \mathrm{O}_{3}$, полученные методом ионно-плазменного распыления. Выявлена зависимость магнитных свойств кобальта от скорости его напыления ионно-плазменным методом распыления и скорости напыления ему предшествующих слоев. Показано, что метод получения буферных слоев позволяет значительно снизить шероховатость поверхности последующих слоев. Полученные буферные слои могут быть использованы в качестве искусственных подложек для выращивания гетероструктур с туннельными переходами.

DOI: 10.21883/JTF.2019.02.47082.198-18

\section{Введение}

В последнее время актуальной проблемой остается исследование механизмов, ответственных за формирование физических свойств тонкопленочных структур в системах ферромагнитный металл/диэлектрик/полупроводник (ФММ/Д/ПП). В структурах ФММ/ПП появляется возможность управлять транспортными свойствами, манипулируя спиновыми состояниями электронов [1-3]. Например, появляется возможность хранить, обрабатывать и передавать информацию в одном электронном чипе. Весьма перспективным направлением исследования является эффект гигантского магнетосопротивления.

Так, в двуслойной структуре ФММ/ПП Co/Ge обнаружено, что наличие переходного слоя влияет на магнитное поведение и магниторезистивный эффект системы [4]. Такой интерфейс между слоями в зависимости от скорости осаждения и температуры подложки может быть довольно размытым, так как большое влияние имеют условия получения, шероховатость в структуре и, как следствие, многофазность в магнитном отношении. Переходный слой может уменьшать магнитную анизотропию, т.е. имеет место конкуренция вкладов от переходного и кобальтового слоев.

Добавление тонких диэлектрических прослоек (окислов и др.), также является перспективным направлением. Использование окисла алюминия является перспективным в качестве диэлектрического затвора для использования в полевых транзисторах $[5,6]$, в качестве просветляющего слоя для оптических зеркал полупроводниковых лазеров [7] и др. [8,9]. При введении диэлектрических прослоек в структуру ФММ/ПП могут возникать туннельные структуры.
В системе типа ферромагнитный металл/ $\mathrm{SiO}_{2} / \mathrm{Si}$ с использованием в качестве ФММ $\mathrm{CoSi}$ или $\mathrm{FeSi}$ в очень тонком слое металла на границе между пленкой и кремниевой подложкой при $250-270 \mathrm{~K}$ обнаружено, что сопротивление испытывает резкий переход [10]. Определенную роль здесь играет ферромагнитное состояние слоя металла, что очень необычно для спинзависимого туннелирования электронов через интерфейс $\mathrm{SiO}_{2} / p$-Si-структуры. Такие особенности обусловлены существованием барьера Шоттки в системе металл/диэлектрик/полупроводник.

Поэтому не удивительно, что магнитные туннельные структуры и тонкопленочные структуры с туннельными переходами, когда ток течет вдоль интерфейсов, привлекают внимание исследований [11-15].

Но получение качественных границ раздела (интерфейсов) между слоями структуры с требуемыми свойствами является довольно сложной задачей.

Получение тонких пленок оксида алюминия ионноплазменным распылением является слабо изученным направлением. Наиболее отработаны методы получения $\mathrm{Al}_{2} \mathrm{O}_{3}$ с использованием электронно-лучевого испарения [8] и магнетронное распыление [16] Конденсация оксида алюминия сопровождается фазовыми превращениями, степень завершенности которых, а следовательно, и эксплуатационные свойства зависят от способа конденсации, температуры подложки, толщины сформированной пленки, чистоты оксида алюминия и ряда других факторов.

Таким образом, в таких системах на первый план выходит изучение влияния границ раздела слоев на формирование структуры и ее физических свойств, в частности, магнитных свойств и на спин-зависимый транспорт. Для исследования выбраны образцы $\mathrm{Al}_{2} \mathrm{O}_{3} / \mathrm{Ge}$ $p / \mathrm{Al}_{2} \mathrm{O}_{3} / \mathrm{Co}$. В качестве полупроводника выступал слой 
Таблица 1. Скорости и толщины слоев структуры $\mathrm{Al}_{2} \mathrm{O}_{3} / \mathrm{Ge}-p / \mathrm{Al}_{2} \mathrm{O}_{3} / \mathrm{Co}$

\begin{tabular}{c|c|c|c|c}
\hline Тип пленки & Скорость $\mathrm{Al}_{2} \mathrm{O}_{3} /$ толщина & Скорость Ge-р/толщина & Скорость $\mathrm{Al}_{2} \mathrm{O}_{3} /$ толщина & Скорость Со/толщина \\
\hline 1 & $0.05 \mathrm{~nm} / \mathrm{min} / 33 \mathrm{~nm}$ & $2.4 \mathrm{~nm} / \mathrm{min} / 54 \mathrm{~nm}$ & $0.05 \mathrm{~nm} / \mathrm{min} / 4.7 \mathrm{~nm}$ & $1.2 \mathrm{~nm} / \mathrm{min} / 104.7 \mathrm{~nm}$ \\
\hline 2 & $0.55 \mathrm{~nm} / \mathrm{min} / 220 \mathrm{~nm}$ & $14.4 \mathrm{~nm} / \mathrm{min} / 31 \mathrm{~nm}$ & $0.55 \mathrm{~nm} / \mathrm{min} / 16 \mathrm{~nm}$ & $7.2 \mathrm{~nm} / \mathrm{min} / 106 \mathrm{~nm}$
\end{tabular}

германия, легированный бором и, следовательно, обладающий проводимостью $p$-типа. В качестве изолирующего слоя между подложкой и Ge- $p$ был выбран $\mathrm{Al}_{2} \mathrm{O}_{3}$, так как данный материал имеет уникальные электрофизические и оптические свойства, высокую твердость, термостойкость, химическую инертность и теплозащитные характеристики.

\section{Методика эксперимента}

Структуры $\mathrm{Al}_{2} \mathrm{O}_{3} / \mathrm{Ge}-p / \mathrm{Al}_{2} \mathrm{O}_{3} / \mathrm{Co}$ были получены методом ионно-плазменного напыления при базовом давлении $P=0.1 \mathrm{~Pa}$ в атмосфере аргона. В качестве материала подложки использовался кремний (001), предварительно очищенный методом ионно-плазменного травления в рабочей камере, непосредственно перед процессом напылением. Напыление проводилось на вращающуюся подложку при ее температуре $T \approx 373 \mathrm{~K}$.

Было получено два типа образцов с отличием скоростей осаждения для $\mathrm{Al}_{2} \mathrm{O}_{3}$ в 10 раз, а для $\mathrm{Ge}-p$ и Со в 5 раз. В табл. 1 представлены средние скорости и толщины полученных структур.

Кроме того, для анализа параметров, полученных для многослойных пленок $\mathrm{Al}_{2} \mathrm{O}_{3} / \mathrm{Ge}-p / \mathrm{Al}_{2} \mathrm{O}_{3} / \mathrm{Co}$, были получены пленки чистого кобальта на аналогичную подложку, предварительно очищенную методом ионноплазменного травления:

1-й тип: скорость $1.2 \mathrm{~nm} / \mathrm{min} /$ толщина $\sim 100 \mathrm{~nm}$;

2-й тип: скорость $7.2 \mathrm{~nm} / \mathrm{min} /$ толщина $\sim 100 \mathrm{~nm}$.

ТЕМ-изображение поперечного сечения структуры получено на просвечивающем электронном микроскопе Hitachi HT7700. Усредненные толщины определялись из полученных ТЕМ-изображений. Структура поверхности пленок исследовалась на атомном силовом микроскопе Veeco Multi Mode (разрешение $1 \mathrm{~nm}$ ). Магнитные данные были получены на СКВИД-магнетометре (MPMS_XL фирмы „Quantum Design“), действующем в диапазоне температур $T=4.2-300 \mathrm{~K}$ и в магнитных полях $H \leq 800$ Ое в геометрии, когда магнитное поле лежало в плоскости пленки. Перед каждым измерением пленка сначала помещалась в демагнетизатор и затем охлаждалась в нулевом магнитном поле (режим ZFC). Также для магнитных измерений был использован метод магнитооптического эффекта Керра (NanoMOKE-2).

\section{Экспериментальные результаты и обсуждение}

ТЕМ-изображения поперечного сечения структуры проиллюстрированы на рис. 1, $a$ и 2,a. Видно, что после обработки подложки ионно-плазменным травлением сформировались сплошные и гладкие межслоевые границы между подложкой и слоем $\mathrm{Ai}_{2} \mathrm{O}_{3}$ для пленок обоих типов (рис. $1, b$ и $2, b)$, с шероховатостью около $1-2 \mathrm{~nm}$. На подложке виден слой оксида кремния толщиной 4-5 nm. Далее для пленок 1-го типа (рис. 1,a) шероховатость на границах между последующими слоями изменяется слабо, а для пленок 2-го типа увеличивается очень резко (рис. 2, $b$ ).

Морфология пленок $\mathrm{Al}_{2} \mathrm{O}_{3} / \mathrm{Ge}-p / \mathrm{Al}_{2} \mathrm{O}_{3} / \mathrm{Co}$ исследовалась методом атомно-силовой микроскопии. На рис. 3

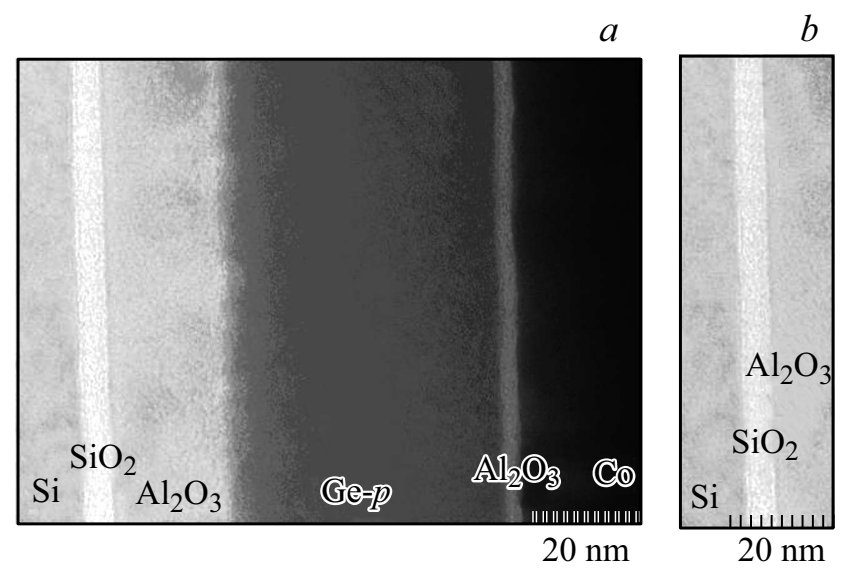

Рис. 1. ТЕМ-изображения пленок $\mathrm{Al}_{2} \mathrm{O}_{3} / \mathrm{Ge}-p / \mathrm{Al}_{2} \mathrm{O}_{3} / \mathrm{Co}(a)$ и интерфейса: подложка/ $\mathrm{Al}_{2} \mathrm{O}_{3}(b)$ 1-й тип образцов.
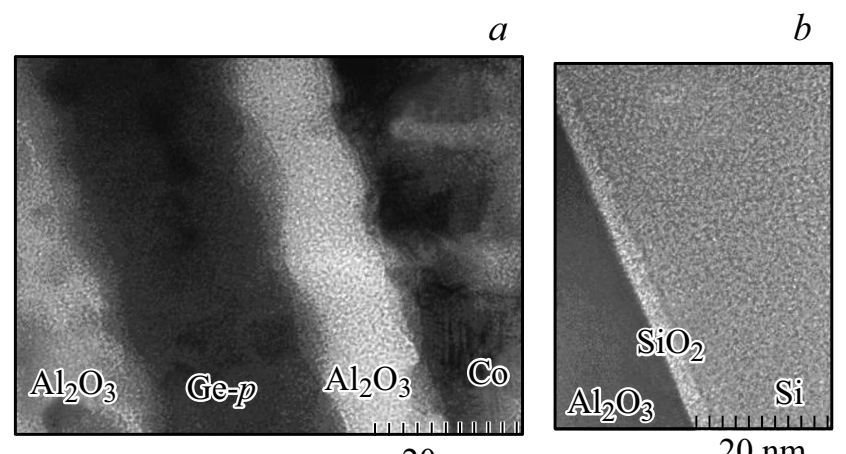

Рис. 2. ТЕМ-изображения пленок $\mathrm{Al}_{2} \mathrm{O}_{3} / \mathrm{Ge}-p / \mathrm{Al}_{2} \mathrm{O}_{3} / \mathrm{Co}(a)$ и интерфейса: подложка $/ \mathrm{Al}_{2} \mathrm{O}_{3}(b)$ 2-й тип образцов. 

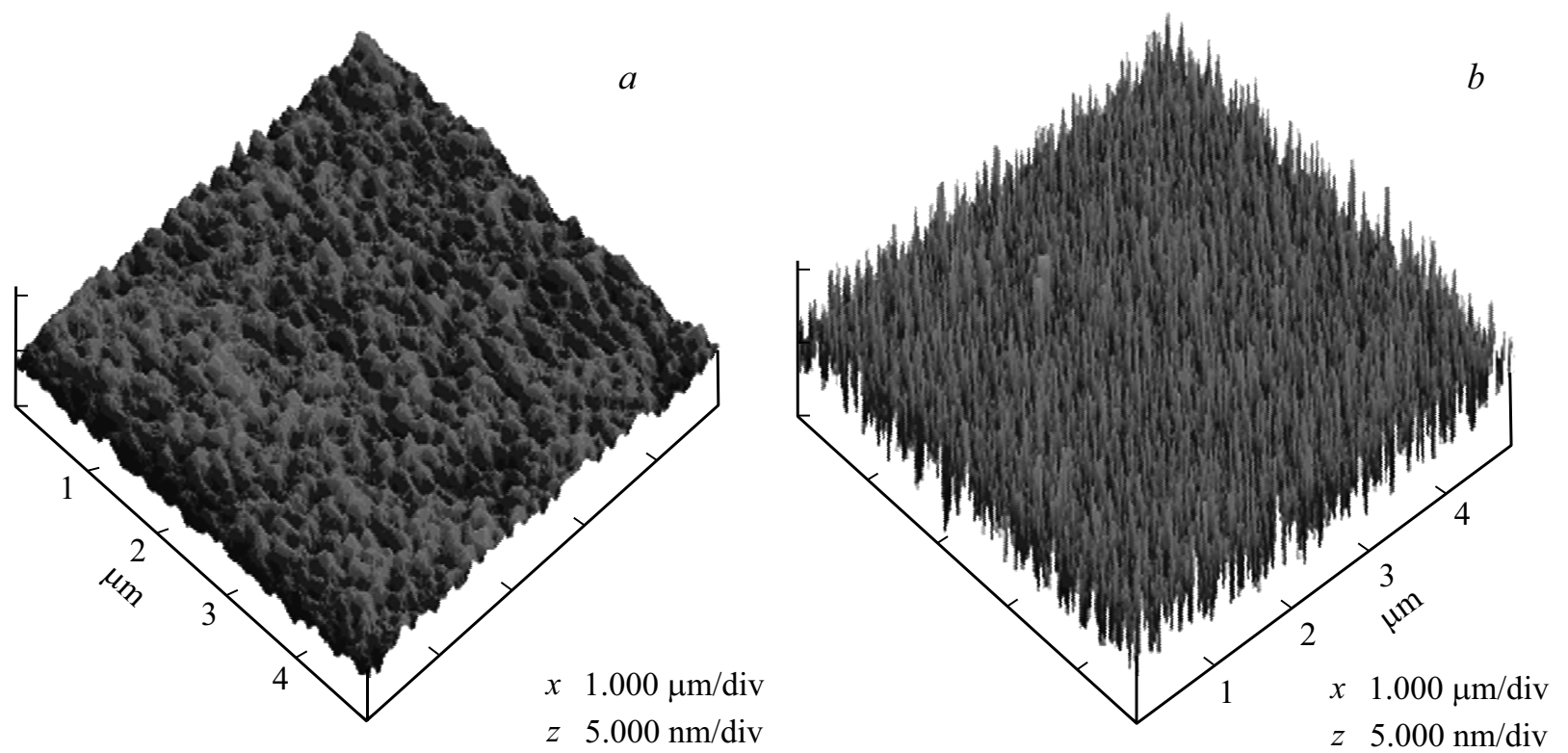

Рис. 3. Атомно-силовая микроскопия пленок $\mathrm{Al}_{2} \mathrm{O}_{3} / \mathrm{Ge}-p / \mathrm{Al}_{2} \mathrm{O}_{3} / \mathrm{Co}: a$ - малая скорость осаждения (1-й тип образцов); $b-$ высокая скорость осаждения (2-й тип образцов).

Co

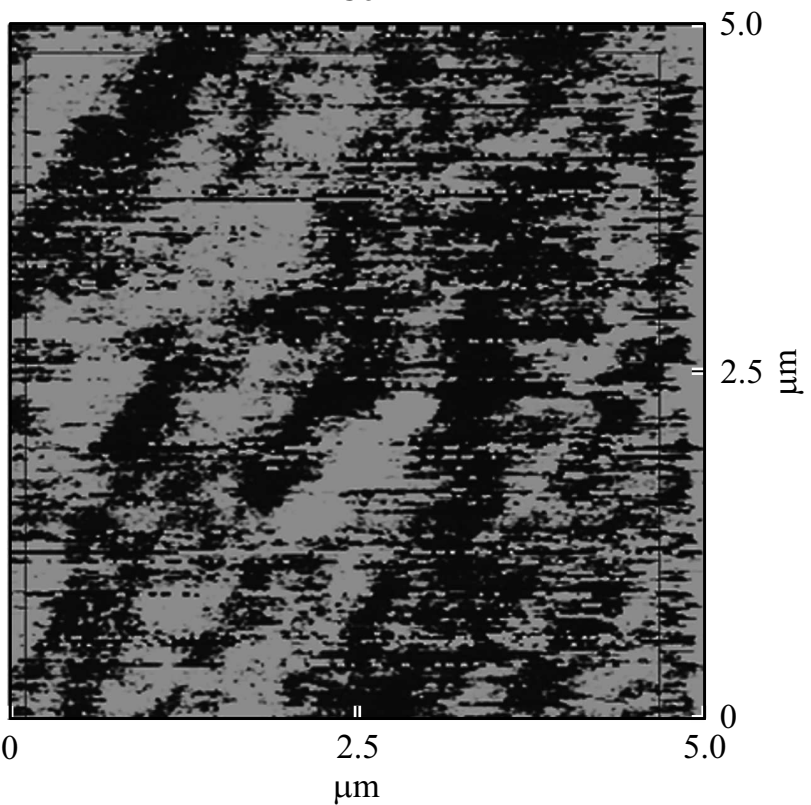

$\mathrm{Al}_{2} \mathrm{O}_{3} / \mathrm{Ge}-p / \mathrm{Al}_{2} \mathrm{O}_{3} / \mathrm{Co}$

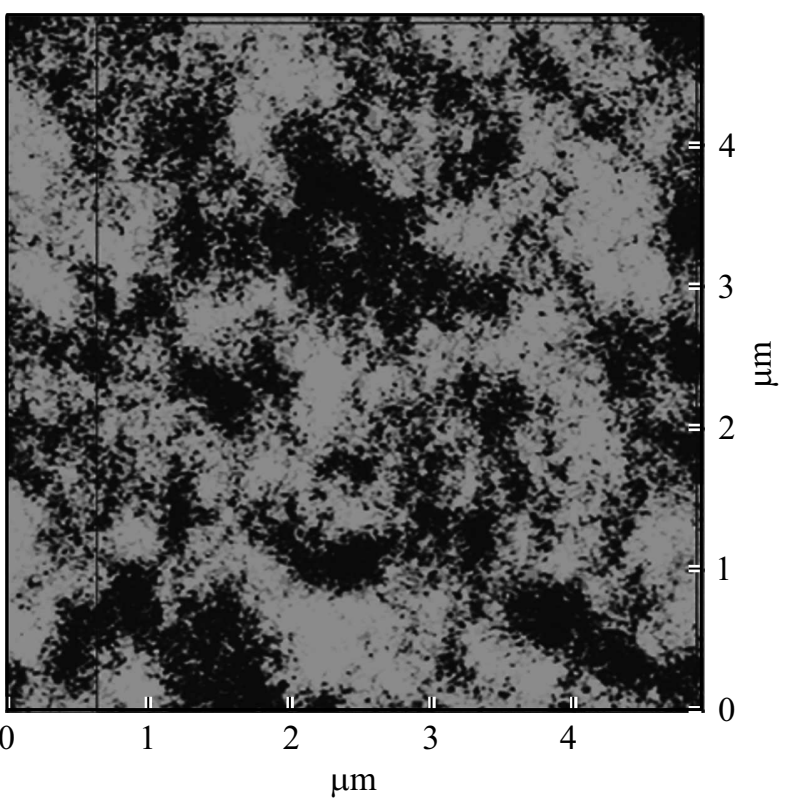

Рис. 4. Магнитная шероховатость образцов Со и $\mathrm{Al}_{2} \mathrm{O}_{3} / \mathrm{Ge}-p / \mathrm{Al}_{2} \mathrm{O}_{3} / \mathrm{Co}$ 1-го типа.

Таблица 2. Параметры шероховатости для пленок 1-го и 2-го типа структуры $\mathrm{Al}_{2} \mathrm{O}_{3} / \mathrm{Ge}-p / \mathrm{Al}_{2} \mathrm{O}_{3} / \mathrm{Co}$ и Со

\begin{tabular}{l|c|r|r|r}
\hline \multirow{2}{*}{ Усредненный параметр } & \multicolumn{2}{|c|}{ 1-й тип } & \multicolumn{2}{c}{2 -й тип } \\
\cline { 2 - 5 } & $\mathrm{Al}_{2} \mathrm{O}_{3} / \mathrm{Ge}-p / \mathrm{Al}_{2} \mathrm{O}_{3} / \mathrm{Co}$ & $\mathrm{Co}$ & $\mathrm{Al}_{2} \mathrm{O}_{3} / \mathrm{Ge}-p / \mathrm{Al}_{2} \mathrm{O}_{3} / \mathrm{Co}$ & \multicolumn{1}{c}{ Со } \\
\hline $\mathrm{Rms}(\mathrm{Rq})$ & $0.415 \mathrm{~nm}$ & $2.850 \mathrm{~nm}$ & $1.226 \mathrm{~nm}$ & $4.589 \mathrm{~nm}$ \\
Mean rougness $(\mathrm{Ra})$ & $0.329 \mathrm{~nm}$ & $2.000 \mathrm{~nm}$ & $0.957 \mathrm{~nm}$ & $2.835 \mathrm{~nm}$ \\
Max height $(\mathrm{Rmax})$ & $3.296 \mathrm{~nm}$ & $27.115 \mathrm{~nm}$ & $17.168 \mathrm{~nm}$ & $30.616 \mathrm{~nm}$ \\
10 pt mean $(\mathrm{Rz})$ & $3.025 \mathrm{~nm}$ & $15.970 \mathrm{~nm}$ & $12.864 \mathrm{~nm}$ & $20.453 \mathrm{~nm}$
\end{tabular}


Таблица 3. Параметры магнитной шероховатости для пленок 1-го и 2-го типа структуры $\mathrm{Al}_{2} \mathrm{O}_{3} / \mathrm{Ge}^{-p} / \mathrm{Al}_{2} \mathrm{O}_{3} / \mathrm{Co}$ и Сo

\begin{tabular}{l|c|r|r|r}
\hline \multirow{2}{*}{ Усредненный параметр } & \multicolumn{2}{|c|}{ 1-й тип } & \multicolumn{2}{c}{2 -й тип } \\
\cline { 2 - 5 } & $\mathrm{Al}_{2} \mathrm{O}_{3} / \mathrm{Ge}-p / \mathrm{Al}_{2} \mathrm{O}_{3} / \mathrm{Co}$ & Cо & $\mathrm{Al}_{2} \mathrm{O}_{3} / \mathrm{Ge}-p / \mathrm{Al}_{2} \mathrm{O}_{3} / \mathrm{Co}$ & \multicolumn{1}{c}{ Cо } \\
\hline Rms (Rq) & $0.328 \mathrm{~nm}$ & $0.816 \mathrm{~nm}$ & $0.988 \mathrm{~nm}$ & $1.072 \mathrm{~nm}$ \\
Mean rougness (Ra) & $0.262 \mathrm{~nm}$ & $0.599 \mathrm{~nm}$ & $0.672 \mathrm{~nm}$ & $0.816 \mathrm{~nm}$ \\
Max height (Rmax) & $2.913 \mathrm{~nm}$ & $12.813 \mathrm{~nm}$ & $36.106 \mathrm{~nm}$ & $14.383 \mathrm{~nm}$ \\
10 pt mean (Rz) & $2.519 \mathrm{~nm}$ & $11.583 \mathrm{~nm}$ & $21.480 \mathrm{~nm}$ & $12.508 \mathrm{~nm}$
\end{tabular}

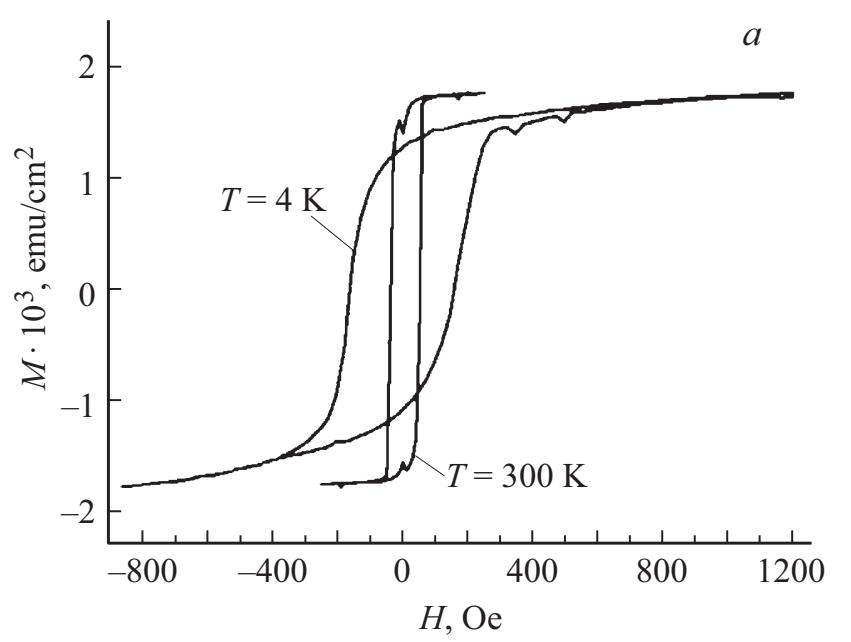

$b$

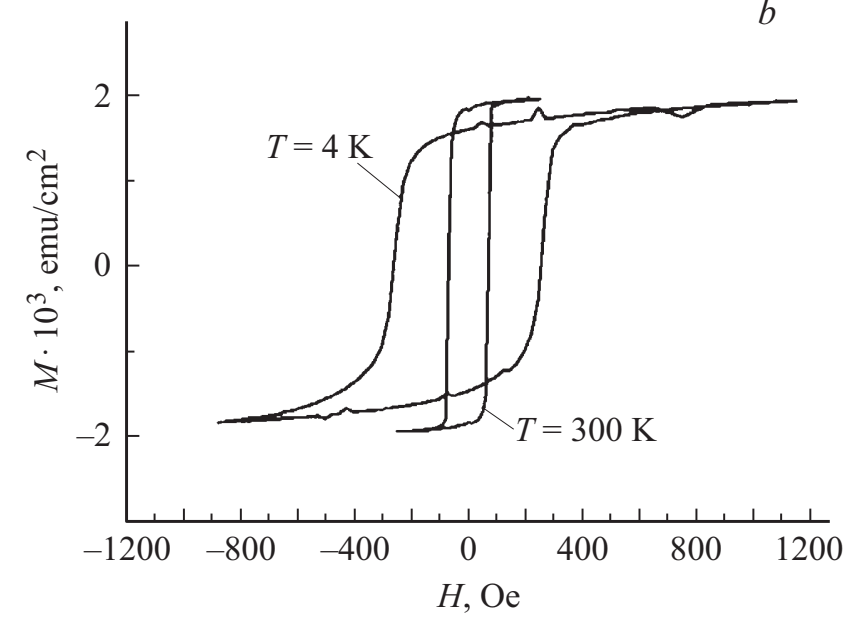

Рис. 5. Петли гистерезиса для чистого слоя кобальта при $T=300$ и $4 \mathrm{~K}: a-1$-й тип образцов (медленные); $b-2$-й тип образцов (быстрые).

представлены результаты для 1-го и 2-го типа сразу после напыления.

Также были получены параметры шероховатости верхнего слоя кобальта для всех образцов чистого кобальта и многослойных пленок $\mathrm{Al}_{2} \mathrm{O}_{3} / \mathrm{Ge}-p / \mathrm{Al}_{2} \mathrm{O}_{3} / \mathrm{Co}$. В табл. 2 представлены параметры шероховатости для пленок 1-го и 2-го типа для некоторых образцов. Из анализа шероховатостей определено, что для пленки чистого кобальта при уменьшении его скорости напыления шероховатость уменьшается в 2 раза. Но для многослойной пленки $\mathrm{Al}_{2} \mathrm{O}_{3} / \mathrm{Ge}-p / \mathrm{Al}_{2} \mathrm{O}_{3} / \mathrm{Co}$ при снижении скорости осаждения каждого слоя шероховатость верхнего слоя кобальта уменьшается в 3-5 раз. Таким образом, существует влияние скорости осаждения промежуточных слоев на шероховатость верхнего слоя.

Также на атомно-силовом микроскопе с использованием магнитных кантилеверов были получены изображения, характеризующие распределение намагниченности в данных пленках. На рис. 4 представлены изображения магнитного контраста пленок чистого кобальта и $\mathrm{Al}_{2} \mathrm{O}_{3} / \mathrm{Ge}-p / \mathrm{Al}_{2} \mathrm{O}_{3} / \mathrm{Co}$ образцов 1-го типа. Используя метод определения шероховатости поверхности для магнитного контраста, можно оценить степень неоднородности магнитного момента образца.

В табл. 3 приведены параметры „магнитной шероховатости“ для тех же образцов, что и в табл. 2.

Из рис. 4 видно, что магнитная поверхность многослойной пленки 1-го типа в отличие от пленки чистого кобальта более мелкодисперсная независимо от скорости напыления. По данным таблицы можно заключить, что значения „магнитных шероховатостей“ при более медленной скорости осаждения в многослойных структурах $\mathrm{Al}_{2} \mathrm{O}_{3} / \mathrm{Ge}-p / \mathrm{Al}_{2} \mathrm{O}_{3} / \mathrm{Co}$ снижаются в $3-5$ раз. Это можно объяснить изменением фазового состава в магнитном отношении и более однородным распределением материалов при осаждении. Для структур $\mathrm{Al}_{2} \mathrm{O}_{3} / \mathrm{Ge}$ $p / \mathrm{Al}_{2} \mathrm{O}_{3} / \mathrm{Co}$ средний размер зерна равен $d \approx 0.84 \mathrm{~nm}$.

При магнитных измерениях на СКВИД-магнетометре, получены петли гистерезиса для слоев $\mathrm{Al}_{2} \mathrm{O}_{3} / \mathrm{Ge}$ $p / \mathrm{Al}_{2} \mathrm{O}_{3} / \mathrm{Co}$ 1-го и 2-го типа (рис. 5,a), а также петли гистерезиса для чистого слоя кобальта без подслоев, 1-го и 2-го типа (рис. 6).

Из анализа петель следует, что для чистого слоя кобальта (рис. 5) при малых скоростях осаждения (1-й тип) коэрцитивная сила при комнатной температуре порядка $50 \mathrm{Oe}$, а при понижении температуры до $4 \mathrm{~K}$, увеличивается до 200 Ое. Для больших скоростей (2-й тип) коэрцитивная сила при комнатной температуре порядка $70 \mathrm{Oe}$, и при понижении температуры до $4 \mathrm{~K}$, увеличивается до 250 Ое.

Для системы $\mathrm{Al}_{2} \mathrm{O}_{3} / \mathrm{Ge}-p / \mathrm{Al}_{2} \mathrm{O}_{3} / \mathrm{Co}$ (рис, 6, $a$ ) при малых скоростях (1-й тип) коэрцитивная сила при комнатной температуре порядка $100 \mathrm{Oe}$, а при понижении температуры до $4 \mathrm{~K}$, увеличивается до 160 Ое. Для больших скоростей (2-й тип, рис. $6, b)$ коэрцитивная сила 


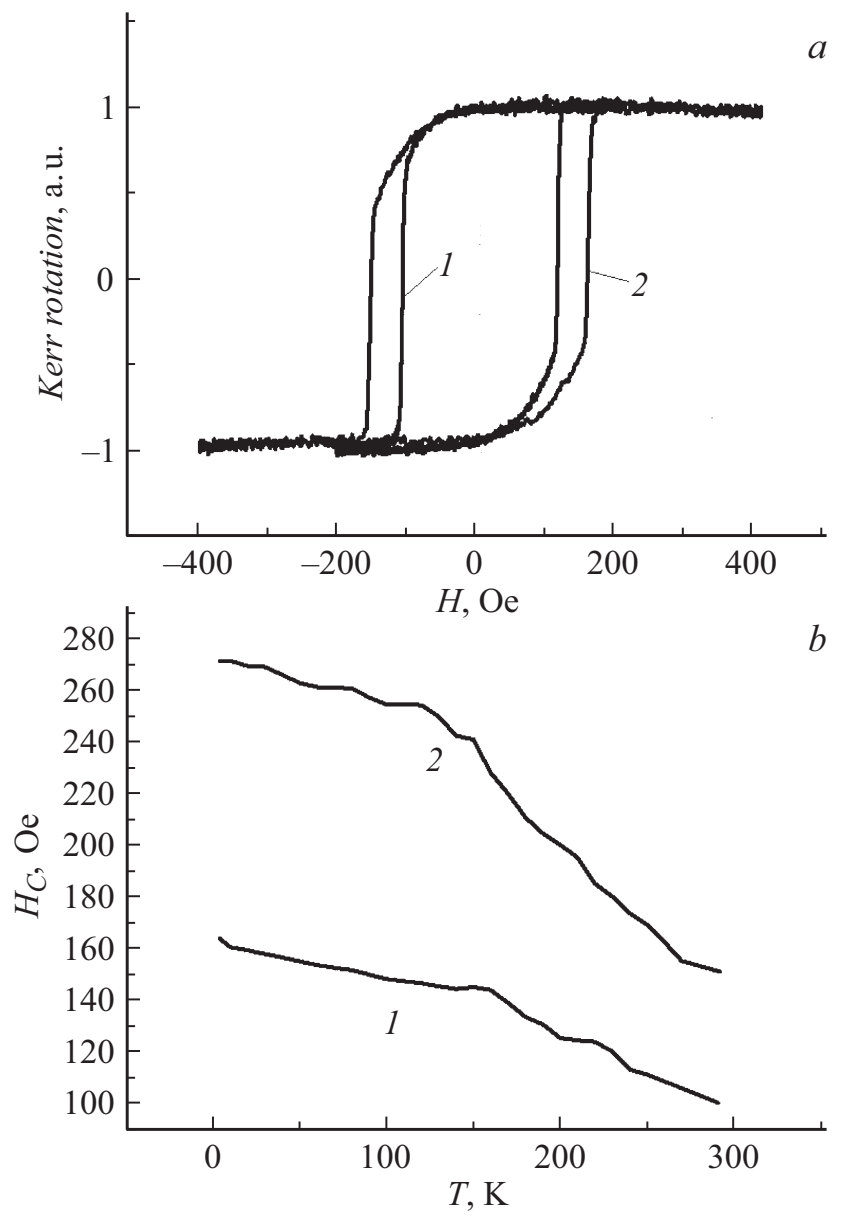

Pис. 6. $a-$ петли гистерезиса при $T=300 \mathrm{~K} ; b-$ зависимость коэрцитивной силы от температуры, образцы 1-го и 2-го типа $\mathrm{Al}_{2} \mathrm{O}_{3} / \mathrm{Ge}-p / \mathrm{Al}_{2} \mathrm{O}_{3} / \mathrm{Co}$.

при комнатной температуре порядка 160 Ое, и при понижении температуры до $4 \mathrm{~K}$, увеличивается до 280 Ое.

Как известно[17], с ростом скорости осаждения кобальта увеличивается средний размер зерна пленок Со и изменяется рельеф поверхности: он становится более неоднородным, что и видно здесь из результатов микроскопии и магнитных измерений. Но кроме этого, из температурных зависимостей коэрцитивной силы (рис. $6, b$ ) для системы $\mathrm{Al}_{2} \mathrm{O}_{3} / \mathrm{Ge}-p / \mathrm{Al}_{2} \mathrm{O}_{3} / \mathrm{Co}$ видно, что различна скорость изменения коэрцитивной силы при изменении температуры (крутизна кривой).

Видно, что при одной и той же скорости напыления кобальта чистого и в системе $\mathrm{Al}_{2} \mathrm{O}_{3} / \mathrm{Ge}-p / \mathrm{Al}_{2} \mathrm{O}_{3} /$ Со коэрцитивные силы отличаются в два и более раз (рис. $6, b$ ). Известно, что при уменьшении скорости осаждения кобальта доля гексагональной фазы уменьшается, и появляются дополнительные фазы. Таким образом, отличие коэрцитивных сил образцов и крутизна температурных зависимостей коэрцитивных сил может быть связана со скоростью осаждения подслоев кобальта в системе, так как рельеф поверхности зависит от скорости осаждения предыдущего слоя и соответственно влияет на структуру последующих слоев. А именно изменение коэрцитивной силы в системах $\mathrm{Al}_{2} \mathrm{O}_{3} / \mathrm{Ge}-p / \mathrm{Al}_{2} \mathrm{O}_{3} /$ Со связано с анизотропией на интерфейсе.

\section{Заключение}

$\mathrm{B}$ результате исследований системы $\mathrm{Al}_{2} \mathrm{O}_{3} / \mathrm{Ge}$ $p / \mathrm{Al}_{2} \mathrm{O}_{3} / \mathrm{Co}$ выявлена зависимость магнитных свойств кобальта от скорости его распыления ионно-плазменным методом и скорости напыления ему предшествующих слоев. Снижение скорости осаждения слоев в многослойной структуре позволяет уменьшить шероховатость границ соседних слоев, средний размер зерна; снизить и стабилизировать коэрцитивную силу. Это может иметь большое значение при создании устройств спинтроники, например магнитных датчиков. Более детальное описание требует учета структуры интерфейса [18], поскольку толщина интерфейса составляет единицы нанометров и в нем формируются новые фазы.

Настоящие исследования ведутся при финансовой поддержке Российского фонда фундаментальных исследований (грант № 18-02-00161-а).

\section{Список литературы}

[1] Ферm A. // УФН. 2008. Т. 178. № 12. С. 1336.

[2] Dushenko S., Koike M., Ando Y., Shinjo T., Myronov M., Shiraishi M. // Phys. Rev. Lett. 2015. Vol. 114. P. 196602.

[3] Song Y., Chalaev O., Hanan Dery // Phys. Rev. Lett. 2014. Vol. 113. P. 167201.

[4] Патрин Г.С., Турпанов И.А., Патрин К.Г., Алексейчик Е., Юшков В.И., Кобяков А.В. // Известия РАН. Серия физическая. 2014. Т. 78. № 1. С. 44.

[5] Lin H.C., Ye P.D., Wilk G.D. // Appl. Phys. Lett. 2005. Vol. 87. P. 182904.

[6] Xuan Y., Wu Y.Q., Lin H.C., Shen T., Peide D.Ye. // IEEE Electron. Dev. Lett. 2007. Vol. 28. P. 935.

[7] Середин П.В., Голощапов Д.Л., Лукин А.Н., Леньшин А.С., Бондарев А.Д., Арсентьев И.Н., Вавилова Л.С., Тарасов И.С. // ФТП. 2014. Т. 48. Вып. 11. С. 1564.

[8] Борисова А.Л., Адеева Д.И., Сладкова В.Н. // Автомат. сварка. 1997. № 9. С. 26.

[9] Крушинская Л.А., Стельмах Я.А. // Вопросы атомной науки и техники. Сер.: Вакуум, чистые материалы, сверхпроводники. 2011. № 19. С. 92.

[10] Dai J., Spinu L., Wang K.-Y., Malkinski L., Tang J. // J. Phys. D: Appl. Phys. 2000. Vol. 33. L65. 12S.

[11] Volkov N.V., Tarasov A.S., Gustajcev A.O., Volkova O.N., Varnakov S.N., Ovchinnikov S.G. // Trans. Nonferrous Met. Soc. China. 2014. Vol. 24. N 10. P. 3158.

[12] Volkov N.V., Tarasov A.S., Eremin E.V., Varnakov S.N., Ovchinnikov S.G., Zharkov S.M. // J. Appl. Phys. 2011. Vol. 109. P. 123924.

[13] Song Y., Dery H. // Phys. Rev. Lett. 2014. Vol. 113. P. 047205.

[14] Txoperena O., Song Y., Qing L., Gobbi M., Hueso L.E., Dery H., Casanova F. // Phys. Rev. Lett. 2014. Vol. 113. P. 146601. 
[15] Ando K., Takahashi S., Ieda J., Kajiwara Y., Nakayama H., Yoshino T., Harii K., Fujikawa Y., Matsuo M., Maekawa S. // J. Appl. Phys. 2011. Vol. 109. P. 103913.

[16] Тесленко-Пономаренко В.В. // Вопросы атомной науки и техники. Сер.: Вакуум, чистые материалы, сверхпроводники. 2003. № 13. Р. 175.

[17] Патрин Г.С., Турпанов И.А., Коблков А.В., Великанов Д.А.,. Патрин К.Г., Ли Л.А., Мальцев В.К., Жарков С.М., Ючков В.И. // ФТТ. 2014. Т. 56. Вып. 2. С. 301.

[18] Патрин Г.С., Кобяков А.В., Турпанов И.А., Патрин К.Г., Раутский М. // ФТТ. 2017. Т. 58. Вып. 5. С. 1034. 